\title{
A IMPORTÂNCIA DO USO DO NOME SOCIAL NO EXAME NACIONAL DO ENSINO MÉDIO - ENEM
}

\author{
Rebeka de França \\ Aluna do $5^{\circ}$ período do Curso de Geografia da IFRN \\ Sayonara Naider Bonfim Nogueira \\ Licenciada em Geografia pela a Universidade Federal de Uberlândia \\ Maria Cristina Cavalcanti Araújo \\ Professora Dr ${ }^{a}$ do Curso de Geografia do IFRN
}

\section{Resumo}

0 presente trabalho traz a tona uma pesquisa de grande importância para o âmbito da geografia que é o estudo da diversidade social no âmbito da ciência geográfica. Estudar o gênero e suas particularidades é de grande valia, pois, consegue compreender as relações sociais. O uso do nome social é um importante direito que as travestis e transexuais conseguiram, um direito constitucional da cidadania. Para isso será necessário passar por postulados que elencam o direito ao uso do nome social, bem como sua aplicabilidade no Exame Nacional do Ensino Médio. Para o desenvolvimento da pesquisa foi realizado pesquisa bibliográfica e em sites com o intuito de fazer levantamento de dados referentes ao ENEM e os inscritos utilizando o nome social. Conclui-se que existem grandes empecilhos que dificultam o acesso das pessoas trans ao exame Nacional do Ensino Médio, caracterizando-se assim, como agressão aos direitos básicos da educação formal.

Palavras-Chaves: Transexuais. Travestis. Geodiversidade. ENEM.

\begin{abstract}
The present works brings to light a research of great importance for the scope of the geography that is the study of the social diversity in the scope of geographic science. Studying gender and its particularities is of great value because it can understand social relations. The use of the social name is an important right that transvestites and transsexuals have achieved, a constitutional right of citizenship. For this it will be necessary to pass through postulates that list the right to the use of the social name, as well as its applicability in the National High School Examination. For the development of the research was carried out bibliographical research and in websites with the intention of compiling data related to the enem and the subscribers using the social name. It is concluded that there are great obstacles that impede the access of trans people to the National Examination of High School, characterizing itself as an aggression to the basic rights of formal education.
\end{abstract}

Keywords: Transsexuals. Shemales. Geodiversity. ENEM. 


\section{INTRODUÇÃO}

O presente trabalho traz como enforque o estudo acerca da importância do uso do nome social no Exame Nacional do Ensino Médio, importante meio de acesso a educação superior e que tem se tornado um grande aparato para o acesso de diferentes grupos sociais, dentre eles as travestis e transexuais (homens e mulheres). A metodologia utilizada foi a pesquisa referencial e bibliográfica em artigos e postulados acerca da temática, bem como em sites governamentais com a finalidade de obter dados pertinentes a pesquisa, como $o$ IBGE e o Ministério da Educação. A opção pela temática diz respeito à condição da autora enquanto pertencente ao grupo "trans", bem como a jornada acadêmica, desde ao uso do nome social no ENEM e sua visão enquanto acadêmica da geografia. Por fim, a pesquisa passará por análise sobre estatísticas concernentes entre anos, desde ao direito e uso do nome social e sua aplicabilidade atual.

\section{O USO E DIREITO A CIDADANIA DA CONSTITUIÇÃO FEDERAL}

Ainda que a Constituição Federal de 1988 traga o conceito de cidadania ampliada, as pessoas trans ainda são excluídas de seus direitos e de uma perspectiva de vida com qualidade, dignidade, respeito, e segurança, o que resulta na marginalização social e na violência psicológica, moral e física.

Desde o início da história a homossexualidade e a transexualidade são má vistas e tidas como doenças, desde então, a sociedade propõe um julgamento injusto e a perseguição a estas populações no intuito de cercear seus direitos e muitas vezes aniquilar suas vidas, muitas vezes em nome de religiões, do preconceito ou pelo machismo.

Como aponta Freire (2013): "A heteronormatividade que cerca as vivências da sexualidade nas chamadas "sociedades ocidentais" faz com que a heterossexualidade seja encarada como a "expressão sexual normal", tudo que foge desse contexto é tido como anormal," Desta forma, é notório a perseguição a este recorte populacional por conta de sua identidade de gênero e orientação sexual que foge do contexto tido como "normal" que rege as culturas ocidentais.

\section{O USO DO NOME SOCIAL NA ATUALIDADE}

No mundo contemporâneo, uma das maiores lutas do movimento trans é o respeito à identidade de gênero, ao nome social e ao tratamento condizente ao gênero. Contudo, o que se ressalta no país é a absoluta ausência de uma legislação que garanta os direitos fundamentais às pessoas trans, como uma lei de identidade de gênero, por exemplo, apesar de vários projetos já terem sido apresentados no Congresso Nacional.

Segundo Bento (2014), foi a partir de 2008, que no Brasil, observam-se mobilizações dos Movimentos Sociais de Lésbicas, Gays, Travestis e Transexuais (LGBT) pela utilização do nome social pelas escolas públicas estaduais nos registros escolares, considerando os altos índices de evasão escolar dessa população, que é impossibilitada de permanecer na escola pública por ser vítima de preconceito e discriminação, ainda usando Bento (2014) é necessário afirmar que a construção do corpo durante o período escolar é extremamente excludente para a população trans, deste modo, prevalece o entendimento de que gênero corresponde a uma construção social. 
A autora explica que essa construção do gênero com base em suas experiências com pessoas que se sujeitam ao processo transexualizador do SUS (hormonioterapia e cirurgia de readequação sexual), conseguem expressar suas angustias e demonstram a ela os principais problemas referentes a esse processo, dentre os principais obstáculos narrados, é possível identificar a ausência da escola, da família e do mais importante - do amor.

Para Cerqueira (2015), em todo o Brasil, o primeiro diploma normativo que se tem notícia a regular a utilização do nome social foi editado pela Secretaria de Estado de Educação do Estado do Pará que, por meio da Portaria n. 16/2008-GS, estabeleceu, de forma sucinta que: "a partir de 02 de janeiro de 2009, todas as Unidades Escolares da Rede Pública Estadual do Pará passarão a registrar, no ato da matrícula dos alunos, o prenome social de travestis e transexuais".

Já a Associação Brasileira de Gays, Lésbicas, Bissexuais, Travestis e Transexuais (ABGLT), afırma que foi a Universidade Federal do Amapá foi pioneira na adoção do nome social para seus alunos. De acordo com Cerqueira (2015), o instituto do "Nome Social", é novo, entretanto está a se difundir em passo acelerado entre os vários entes federativos. 0 nome social é aquele pelo qual as pessoas travestis e transexuais se reconhecem, bem como são identificadas por sua comunidade e em meio comunitário. É, assim sendo, o nome usualmente empregado nas relações diárias do indivíduo, uma vez que a vida diária não exige os rigorismos da exibição de documentos oficiais para interagir com outras pessoas.

\section{A UTILIZAÇÃO DO NOME SOCIAL NO ENEM}

Desde 2014 o Enem travestis e transexuais podem ser identificados/as pelo nome social nos dias e locais de realização das provas. Para isso, os/as candidatos/as necessitam fazer uma solicitação ao Instituto Nacional de Estudos e Pesquisas Educacionais (Inep), como êxito desta política vale salientar que desde que o direito de usar o nome social foi adotado, houve um crescente número de pessoas trans adentrando as portas das universidades, 0 nome social não só convidou a esta população a se submeter ao exame, como abriu as portas do ensino superior para este segmento.

O nome social surge no Enem após várias denúncias e reclamações na mídia pelo constrangimento que pessoas trans sofreram na hora de apresentar o documento de identidade aos fiscais das salas de prova, desde atraso da entrega de caderno de provas pela demora de conferência de dados a relatos de humilhações e discriminação por parte dos fiscais.

Em 2014, 102 pessoas trans usaram o nome social durante a aplicação da prova, em 2015 esse número passou para 278. Em 2016, o número cresceu 46\%, dos 842 pedidos, 408 foram atendidos. De acordo com o Instituto Nacional de Estudos e Pesquisas (Inep), 432 pedidos foram recusados neste ano porque os participantes não encaminharam a documentação exigida em edital. Os outros dois foram de candidatos que conseguiram o registro civil com o nome social. 


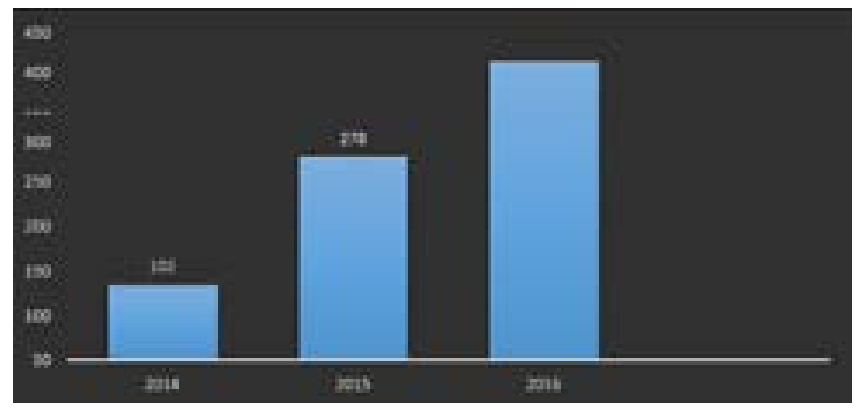

GRÁFICO 1 - INSCRIÇÕES DEFERIDAS COM O USO DO NOME SOCIAL NO ENEM

Fonte: FRANÇA, R. de; NOGUEIRA, S. N. B. com dados do INEP (2017).

Desde 2015, São Paulo é o Estado com o maior número de solicitações atendidas: 89 em 2015 e 180 em 2016. O segundo estado com mais transvestis e transexuais que conquistaram o direito de usar o nome social no Enem deste ano foi Minas Gerais (37), seguido por Rio de Janeiro (35), Paraná (25), Bahia e Rio Grande do Sul (16 cada), Pernambuco e Santa Catarina (11 cada). Os demais estados tiveram menos de dez inscrições cada, desta forma, também pode se apontar a procura nos outros estados que não foram citados devido a pouca procura ou não saberem do uso dessa política. Com estes números foi possível comprovar que esta população, vive em todo o território nacional e solicitou o nome social em quase todos os estados da unidade federativa.

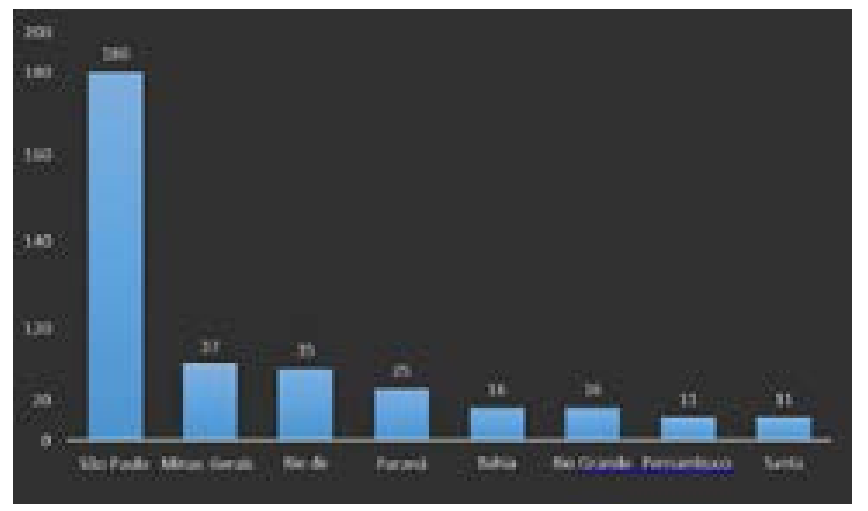

GRÁFICO 2 - O USO DO NOME SOCIAL NO ENEM EM 2016 POR ESTADO

Fonte: FRANÇA, R. de; NOGUEIRA, S. N. B. com dados do INEP.

Dessa forma, os/as candidatos/as travestis e transexuais que realizarão o Exame Nacional do Ensino Médio (Enem) 2017 terão entre 29 de maio e 4 de junho para pedir o uso do nome social no exame. Os pedidos poderão ser feitos a partir das $10 \mathrm{~h}$. Inscrições para a prova, que acontece em 5 e 12 de novembro vão até 19 de maio. A taxa de inscrição, de R\$ 82 , deve ser paga até o dia 24 de maio.

Os interessados deverão enviar cópia do documento de identificação, formulário preenchido e foto recente pelo sistema de inscrição. No dia das provas, as pessoas trans deverão ser tratadas pelo nome com o qual se identificam e também deverão utilizar o banheiro do gênero com o qual se identificam. Para realizar a solicitação, os participantes devem dispor dos seguintes documentos: fotografia nítida, atual, individual, colorida, com fundo branco que enquadre desde a cabeça até os ombros; cópia digitalizada da frente e verso de um dos documentos oficiais com foto; e cópia assinada e digitalizada do formulário de solicitação de atendimento pelo nome social que será disponibilizado na Página do Participante às $10 \mathrm{~h}$ do dia 29 de maio. 


\section{CONCLUSÕES}

Observa-se que com a utilização do nome social e posteriormente ser uma lei e por direito a todos e qualquer indivíduo que traga o gênero como característica social e é de grande valia, pois se for analisar um passado não tão distante, esse direito era irracional e inconstitucional, pois via as transexuais e travestir com um olhar de preconceito patológico.

Embora seja uma grande conquista, há um grande empecilho que é a comprovação para a utilização do nome social, pois faz o indivíduo passar por um momento de "comprovação de existência", algo que caracteriza que algum deste grupo esteja mentindo ou utilizando o direito de má fé. Como consequência disto há certo receio em participar de processos seletivos como o ENEM.

Em suma, é uma conquista a ser trabalhada e discutida. Porém, compreendemos que ainda há muito a se avançar. Precisamos aumentar fóruns de debates e discussões que tratem em deixar o acesso ao nome social algo mais simplificado e objetivo, sem as necessidades de grandes comprovações. 0 exercício da cidadania dá ao ser humano seu poder de escolha, sua liberdade de ser o que quer nesse sentido, entendemos que esse direito ainda está sendo tolhido, o que dificulta às pessoas trans o acesso ao direito básico e universal que é o da educação formal.

\section{REFERÊNCIAS}

1. AGÊNCIA BRASIL. Aumenta o uso do nome social por travestis e transexuais no Enem 2016. Último Segundo, IG, 12/10/2016. Disponível em: <http://ultimosegundo.ig.com. br/educacao/2016-10-12/enem-2016.html>. Acesso em 12 mai. 2017.

2; BENTO, Berenice. A reinvenção do corpo: sexualidade e gênero na experiência transexual. $2^{\mathrm{a}}$ edição - Natal: EDUFRN. 2014.

3. BENTO, Berenice. Nome social para pessoas trans: cidadania precária e gambiarra legal. Contemporânea - Revista de Sociologia da UFSCar, São Carlos, v. 4, n. 1, jan.jun. 2014. p. 165-182. Disponível em: <http://www.contemporanea.ufscar.br/index.php/ contemporanea/article/viewFile/197/ 101>. Acesso em 12 mai. 2017. 